\title{
EFFECTS OF AMINOPHYLLINE, PROXYPHYLLINE AND A PROXYPHYLLINE-MELILOTUS EXTRACT-RUTIN MIXTURE (THEOESBERIVEN) ON THE HEART AND THE CORONARY CIRCULATION
}

\author{
Keisuke TAKEDA, Yumi KATANO, Yoshito NAKAGAWA, \\ Tokumasa TSUKADA, Mikio NAKAZAWA, Takeshi OTORI"* \\ and Shoichi IMAI \\ Department of Pharmacology, Niizata University School of Medicine, \\ Niigaia 951, and * Department of Pharmacology, \\ Yamagata University School of Medicine, Yamagata 990-23, Japan
}

Accepted June 16, 1977

\begin{abstract}
Effects of aminophylline, proxyphylline and a proxyphylline-Melitotus extract-rutin-mixture (theoesberiven) on the heart and coronary circulation were studied in the canine heart-lung preparation supported by a donor in comparison with those of isoproterenol (Isp). All the three muthylxanthines produced an increase in the coronary flow associated with a definite positive inotropic effect. In contrast to the effects of Isp, increase in the heart rate was minimal with these compounds. Myocardial redox potential ( $J \mathrm{Eh}$ ) changed to more negative valucs, although the changes were smaller than that produced by Isp. Since it was found that these substances produced a disproportionately greater increase in the corunary now as compared with an increase in the myocardial oxygen consumption, the etiects of these substances on the myocardial high-energy phosphate compounds were also studied in the isolated pcrfused heart preparation of the guinca pig. Alt the three compounds produced a reduction of the creatine phosphate $(\mathrm{Cr}-\mathrm{P}) /(\mathrm{Cr}-\mathrm{p}+$ Inorganic phosphate) ratio and the energy charge of the adenylate system, in the following order, aminophylline proxyphylline = theoesberiven. Antagonism towards adenosine was found with the three methylxanthines used. In the isolated left atrial preparation of the guinea-pig, aninophylline induced a definite potentiation of the positive inotropic effect of isoproterenol, while the potentiation produced by proxyphylline and theousberiven was minimal.
\end{abstract}

It is well known that methylxanthines increase the diameter of isolated coronary arterial rings and increase the coronary blood flow both in perfused hearts and in in situ hearts (for references see Boyer and Green (1); Wégria (2); Charlier (3)). However, Schmidt (4) characterized these compounds as "an undesirable or malignant vasodilators", since they found a decrease in the oxygen content of the coronary venous blood after administration of these compounds. Moreover, there are numerous studies in man in which no benefit from xanthine therapy was observed (for references, see Charlier (5)).

Nevertheless, sone clinical studies, for example those by Russek (6), gave support to the claim for the beneficial efficacy of the methylxanthines in anginal patients.

In view of this discrepancy, we have undertaken to rcevaluate the effects of methylxanthines on the heart and the coronary circulation, in relation to the effects of these substances 
on the myocardial metabolism. As a representative methylxanthine, aninophylline was chosen and its effects on the heart and the coronary circulation were studied. Since it was demonstrated that the compound produced a disproportionately greater increase in the coronary blood flow as compared with an increase in the myocardial oxygen consumption, the efiects of proxyphylline, another methylxanthine derivative, which, according to Taugner et al. (7) and Roth et al. (8), is almost equipotent a coronary vasodilator as aminophylline, but only half as potent a cardiostimulant, and a proxyphylline-Melilotus extract-rutin mixture (theoesberiven) was also studied, in hopes of finding methylxanthine compounds which are more effective in improving the oxygen supply to the myocardium. To determine the metabolic consequence of the improved oxygen supply to the myocardium produced by aminophylline and related compounds, the effects of the above three compounds on the myocardial redox potential were also studied.

To further characterize the metabolic effect of these substances, the effects of these substances on the high-energy phosphate compounds contents of the myocardium were studied using the isolated perfused heart of guinea pig.

Since it is known that anjinophylline is a competitive antagonist of adenosine $(9,10)$, a regulator substance of the coronary circulation, the antagonism between adenosine and the other two methy Xanihine compounds was studied.

In reent years much attention has been direeted to methylxanthines as potent competitive inhibitors of phosphodiesterase (11). Therefore, the effects of these compounds on the cardiac actions of isoproterenol were also studied.

\section{MATERIAIS AND METHODS}

Expcriments were performed on the canine heart-lung preparation (HLP) supported by a donor, the details of which were described in our previous publication (12). Antagonism towards adenosine was studied in the isolated perfused heart preparation of the guinea pig (Langendorif"s preparation) and modification of the effects of isoproterenol was studied in the isolated atrial preparation of the guinea pig.

\section{Experiments in dog $H L P$}

Mongrel dogs of either sex weighing between 7.5 and $16.5 \mathrm{~kg}$ were anesthetized with sodium pentobarbital $35 \mathrm{mg} / \mathrm{kg}$ i.p. and the heart-lung preparation was prepared. To avoid a gradual deterioration of the preparation, the coronary sinus outflow of the preparation was led to the femoral vein of another larger $\operatorname{dog}(20-40 \mathrm{~kg})$ anesthetized with morphine (1.5 $\mathrm{mg} / \mathrm{kg}$ s.c.)-chloralose ( $45 \mathrm{mg} / \mathrm{kg}$ i.v.)-urethane ( $450 \mathrm{mg} / \mathrm{kg}$ i.v.) and was pumped back as a fresh arterial blood to the venous reservoir of the HLP.

Coronary blood flow of the preparation was estimated as $10 / 6$ of the coronary sinus outflow measured using an clectromagnetic flowmeter (Nihon Kohden MF26) cquipped with a cannulating type probe of $2 \mathrm{~mm}$ internal diameter. In order to calculate the oxygen consumption of the myocardium, the oxygen saturation of the coronary arterial and venous blood was recorded continuously with a Kipp and Zonen Oximeter (C.C. oximeter MO 3) and the hemoglobin concentration of the blood was determined with a hemoglobinometer 
(Erma Optical Works 303).

\section{Isolated perfused heart preparation of the guinea pig}

Male albino guinea pigs weighing between 400 and $500 \mathrm{~g}$ were sacrificed by a blow on the head and the heart was quickly excised. The ascending aorta was cannulated and connected to a non-recirculating perfusion system (hydrostatic pressure $75 \mathrm{~cm} \mathrm{H}_{2} \mathrm{O}$ ) according to the method of Langendorff.

The perfusate was a modified Krebs-Ringer-bicarbonate solution containing $\mathrm{NaCl}$ $127.2 \mathrm{mM}$; $\mathrm{KCl} 4.7 \mathrm{mM}$; $\mathrm{CaCl}_{2} 2.5 \mathrm{mM}$; $\mathrm{KH}_{2} \mathrm{PO}_{4} 1.2 \mathrm{mM}$ and $\mathrm{NaHCO}_{3} 24.9 \mathrm{mM}$ and was equilibrated with $95 \% \mathrm{O}_{2}+5 \% \mathrm{CO}_{2}\left(\mathrm{pH} 7.41-7.45,38^{\circ} \mathrm{C}\right)$. As substrates, $5.5 \mathrm{mM}$ glucose and $2.0 \mathrm{mM}$ sodium pyruvate were added to the perfusate.

Left ventricular isovolumetric pressure was measured with a flaccid saline filled rubber balloon coupled to a pressure transducer (Nihon Kohden MPU-0.5). Pressure pulse dp/dt was obtained with an electronic differentiation system (San-ei Sokki). A cannulating-type probe (1.5 mm internal diameter) of an electromagnetic flowmeter (Statham SP 2201), placed just before the aortic cannula measured the mean coronary flow. Spontaneous heart rate was counted from the electrogram recorded by two serrefine attached to the surface of the right atrium.

Drugs were injected continuously into the rubber tubing leading to the aortic cannula with the aid of a infusion pump (Harvard Apparatus 940). After a 10 minute infusion, the hearts were quickly cut of the cannula and immediately frozen with a Wollenberger clamp, precooled in liquid $\mathrm{N}_{2}$. The frozen tissue was pulverized at liquid $\mathrm{N}_{2}$ temperature with at stainless steel pulverizer consisting of a hollow cylinder and a piston and was homogenized with 2 volumes of $0.6 \mathrm{~N}$ PCA at $0^{\circ} \mathrm{C}$. After centrifugation with a refrigetated centrifuge (3000 rpm for $15 \mathrm{~min}$ ), the residue was honogenized again with 2 volumes of $0.2 \mathrm{~N}$ PCA and centrifiged. Combined supernatant was neutralized with $5 \mathrm{~N} \mathrm{KOH}$. Adenine nucleolides were separated using the thin-layer chromatographic (TLC) method of Jones et al. (13) using polyethyleneimine (PEI) impregnated cellulose plates, and were quantitated directly on the plates by UV absorption, with a dual-wavelength TLC scanner (Shimadzu CS-900). Total phosphate contents (inorganic phosphate plus creatine phosphate) were determined by the method of Fiske and SubbaRow (14) incubating an aliquot of the neutralized muscle extract with the acid-molybdate reagent for $30 \mathrm{~min}$ at $25^{\circ} \mathrm{C}$. Creatine phosphate was determined on a second aliquot after precipitating all the inorganic phosphates with alkaline $\mathrm{CaCl}_{2}$ ( $\mathrm{pH}$ 9), following the method described by Fawaz and Fawaz (15).

\section{Isolated atrial preparation of thr 'suinea pig}

Male albino guinea pigs weighing between 400 and $500 \mathrm{~g}$ were sacrificed by a blow on the head and the atria were quickly cxcised. Left atrial preparations were prepared and suspended vertically in $20 \mathrm{ml}$ organ bath containing Krebs-Henseleit solution aerated with $95 \% \mathrm{O} .5 \% \mathrm{CO}_{2}$ and $\mathrm{kept}$ at a temperature of $32.510 .1^{\circ} \mathrm{C}$. To obtain optimum responses, the initial tensions of the preparations were set at about $0.2 \mathrm{~g}$ and the contractile tension was recorded on an ink-writing oscillograph with a force-displacement transducer 
(Nihon Kohden SB-1T) coupled with a carrier amplifier (Nihon Kohden RP-3). To avoid the initial fluctuations of the preparations, the muscle was left for one hr after mounting. $\Lambda$ s a representative $\beta$-adrenergic agonist, isoproterenol (Isp) was added directly to the organ bath in a cumulative fashion. The resulting changes werc expressed as \% of the maximum changes obtainable in that particular preparation. After a cumulative dose-response curve was obtained for Isp, methylxanthines were administered, the muscle was incubated for 1 hour, and the cumulative dose-response curve for Isp was again established in the presence of methylxanthines.

Compounds used were: l-isoproterenol hydro-

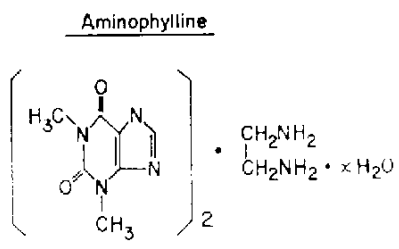

Proxyphyline

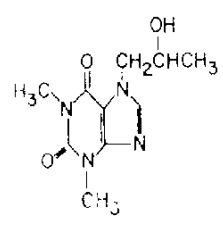

Fici. 1. Chemical structure of proxyphylline and aminophylline.

chloride (Proternol, Nikken Kagaku), adenosine (Sigma Chemical), aminophylline (Ncophylline, Eisai), proxyphylline: 7-(3-hydroxypropyl)-theophylline (Monophylline, Yoshitomi) and a proxyphylline-Melilotus extract-rutin mixture (Theoesberiven, Funai). Chemical structure of proxyphylline is depicted in Fig. 1 in comparison with that of aminophylline.

\section{RESULTS}

Canine heart-lung preparation (HLP) supported by a donor

In doses above $3 \mathrm{mg}$, aminophylline produced a dose-related increase in the coronary

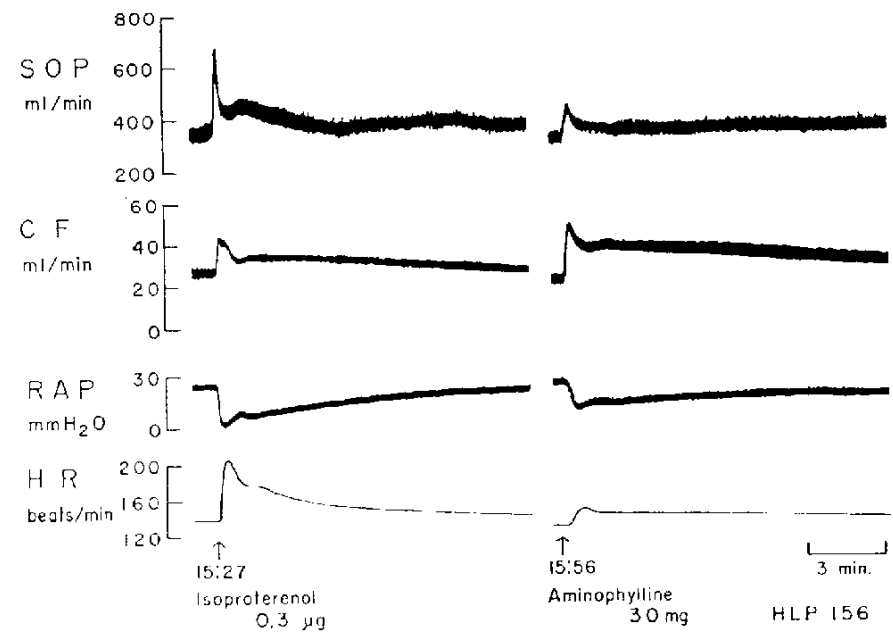

Fig. 2. Liffects of aminophylline on the anine heart-lung preparation supported by a donor as compared with those of isoproterenol (Exp. No. 156; dog, female, $9 \mathrm{~kg}$ : heart weight, $97 \mathrm{~g}$ ). Total blood volume at the beginning was $1000 \mathrm{ml}$. SOP: systemic cardiac output. CF: coronary blood llow. RAP: right atrial pressure. HR: heart rate per minute. 
blood flow which was associated with positive inotropic and chronotropic effects, as shown in Fig. 2. For comparison, effects of 0.3 , g of isoproterenol are also depicted in this figure.

Proxyphylline and theoesberiven produced similar types of dose-related responses, except that the increases in the heart rate produced by these compounds were much smaller than that produced by aminophylline (Fig. 3). Since $0.6 \mathrm{ml}$ of theoesberiven which contained $72 \mathrm{mg}$ of proxyphylline, $30 \mathrm{mg}$ of Melilotus extract (equivalent to $0.3 \mathrm{mg}$ of coumarin) and

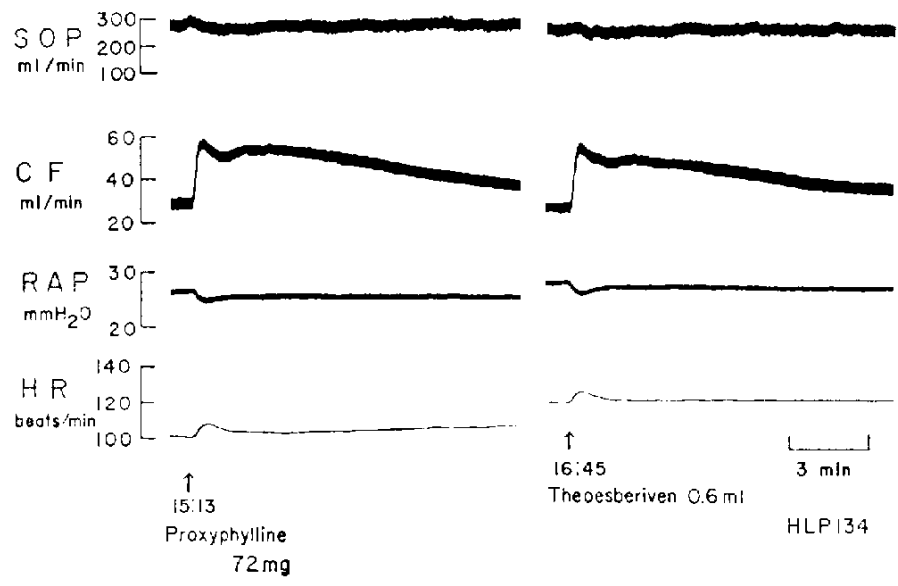

Fig. 3. Elfect of proxyphylline and theoesberiven on the canine heart-lung preparation supported by a donor. Exp. No, 134, dog, male $11 \mathrm{~kg}$; heart weight, $120 \mathrm{~g}$. Total blood volume at the beginning of the experiment was $1500 \mathrm{ml}$. Abbreviations are the same as in Fig. 2.

Aminophylline $30 \mathrm{mg}$

$n=13$

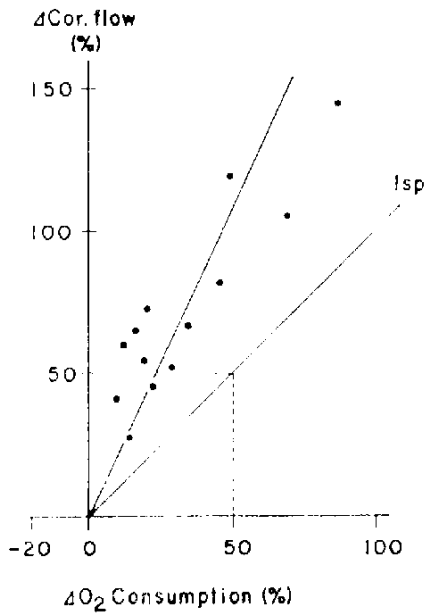

Froxyphylline 36-72mg

$n=8$

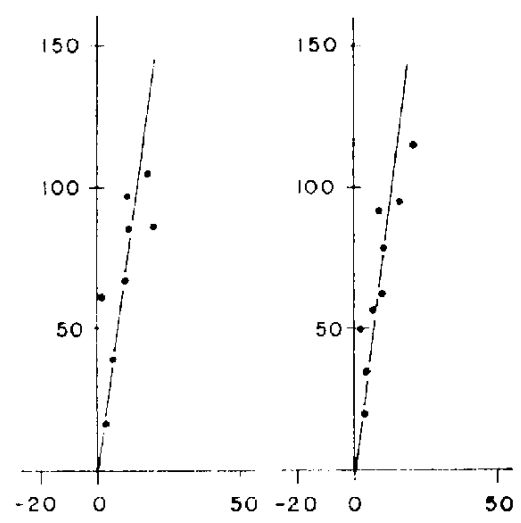

Fic. 4. Effects of methylxanthines on the relation between the changes in the coronary flow and the changes in the myocardial oxygen consumption. Jcor. flow (\%). changes in the coronary flow expressed as percent of the initial valuc. $\mathrm{SO}_{2}$ consumption ( $\%$ ): changes in the myocardial oxygen consumption expressed as percent of the initial value. 
$15 \mathrm{mg}$ of rutin produced almost the same increase in the coronary blood flow as well as positive inotropic and chronotropic effects as $72 \mathrm{mg}$ of proxyphylline, it may be inferred that the Melilotus extract and rutin contained in theoesberiven was without cffects on the heart and the coronary circulation.
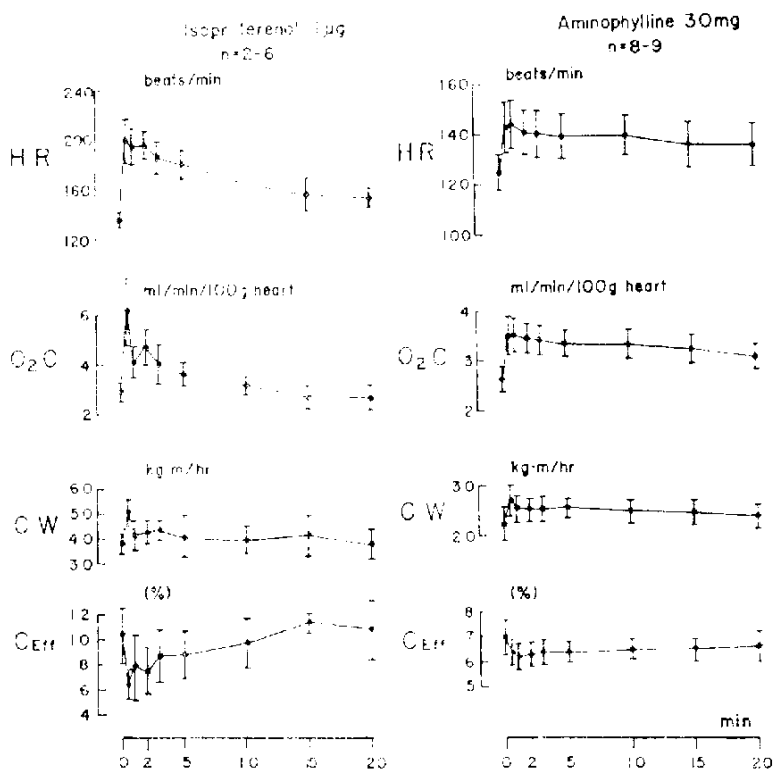

Fis. 5. Effects of aminophylline on the heart rate (HR) myocardial oxygen consumption $\left(\mathrm{O}_{2} \mathrm{C}\right)$, cardiac work $(\mathrm{CW})$ and myocardial efficiency $(\mathrm{C}$, er $\mathrm{r})$ as compared with those of isoproterenol.

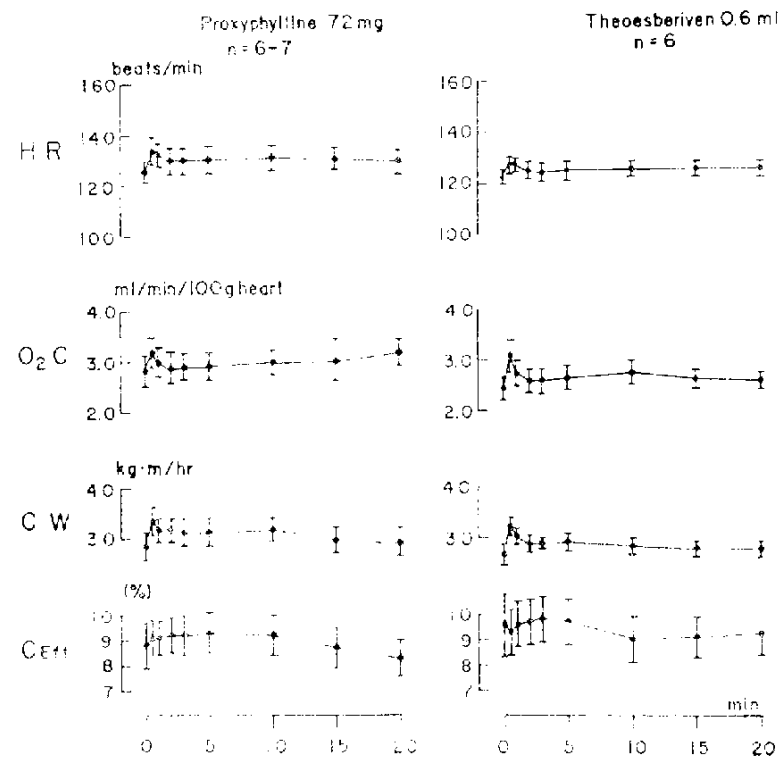

Fig. 6. Liffects of proxyphylline and theoesberiven on the heart rate (HR), myocardial oxygen consumption (O.C), cardiac work (CW) and myocardial efficiency $\left(\mathrm{C}_{\mathrm{E} I 1}\right)$. 
Fig. 4 depicts the percent increase in the coronary blood flow produced by the above three compounds as plotted against the percent increase in the myocardial $\mathrm{O}_{2}$ consumption. As is evident from this figure, there was an increase in the myocardial $\mathrm{O}_{2}$ consumption after aminophylline. However, the increase in the coronary blood flow was disproportionately
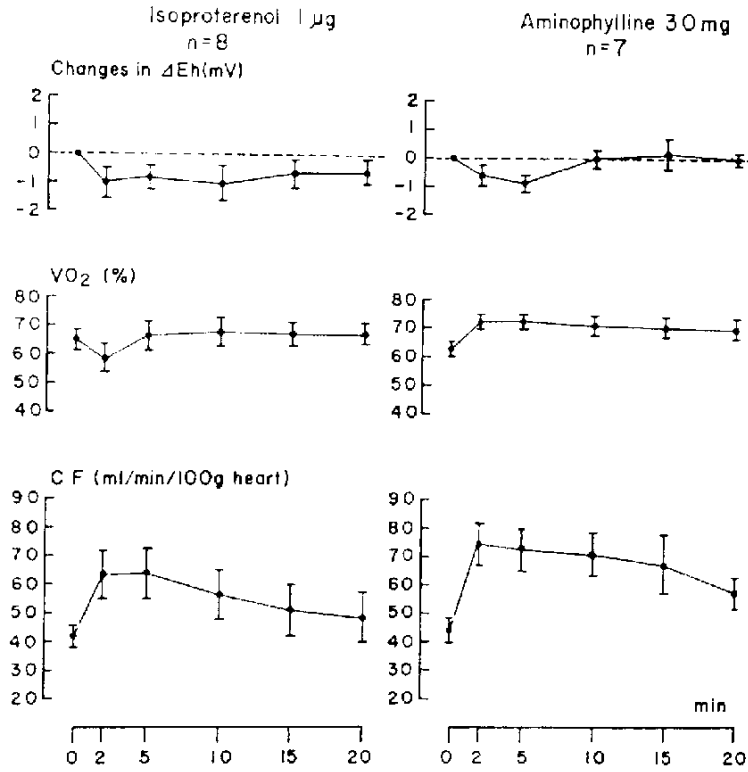

Fig. 7. Effects of aminophylline on the myocardial redox potential ( $\Delta \mathrm{Eh}$ ), coronary sinus blood oxygen content $\left(\mathrm{VO}_{2}\right)$ and coronary flow (CF) as compared with those of isoproterenol.

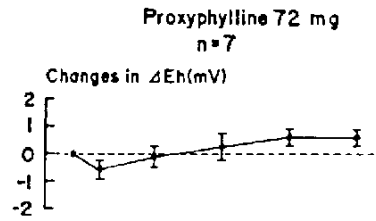

Theoesberlven $0.6 \mathrm{ml}$ $n=7$
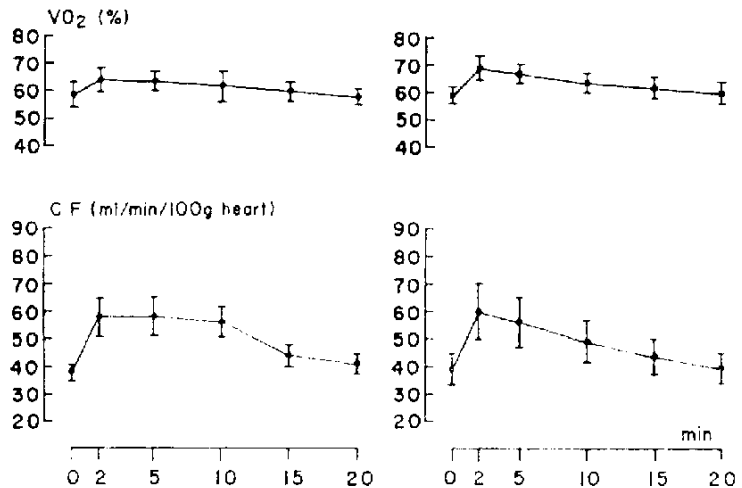

FIG. 8. Effects of proxyphylline and theoesberiven on the myocardial redox potential ( $J$ Eh), coronary sinus blood $\mathrm{O}_{2}$ content $\left(\mathrm{VO}_{2}\right)$ and coronary flow $(\mathrm{CF})$. 
greater, indicating that aminophylline exerted a direct dilatatory effect on the coronary blood vessels. As for proxyphylline and theoesberiven, the increase in the myocardial $\mathrm{O}_{2}$ consumption was still smaller.

Figs. 5 and 6 illustrate the effects of the above three compounds on the heart rate, myocardial oxygen consumption, cardiac work and mechanical efficiency of the heart.

While mechanical efficiency of the heart became lower after aminophylline, an improvement of mechanical efficiency was observed after proxyphylline and theoesberiven. For comparison, the effects of isoproterenol are also depicted in Fig. 5. Isoproterenol produced a far greater decline of the mechanical efficiency due to a larger increase in the myocardial $\mathrm{O}_{2}$ consumption which resulted from a greater increase in the heart rate.

Figs, 7 and 8 depict the effects of these substances on the myocardial redox potential.

Myocardial redox potential changed to more negative values after all three methylxanthine compounds as well as after isoproterenol. However, changes produced by proxyphylline and theoesberiven were smaller than that produced by aminophylline. Isoproterenol was most potent in this respect.

\section{Isolated perfused heart preparation of the guinea pig}

After an equilibration of $1 \mathrm{hr}$, the spontaneous heart rate per minute of the preparation was $252 \pm 3(n=32)$ and the coronary flow per minute $12.1 \pm 0.6 \mathrm{ml}(\mathrm{n}=32)$.

All three methylxanthines produced an increase in the coronary flow together with positive inotropic and chronotropic effects in this preparation. Table 1 lists the percent changes in the coronary flow and the heart rate produced by these compounds. Here,

TABLE 1. Effects of aminophylline, proxyphylline and theoesberiven on the isolated perfused heart preparation of the guinea pig as compared with isoproterenol

\begin{tabular}{lccc}
\hline & $\begin{array}{c}\text { Increase in } \\
\text { coronary flow }(\%)\end{array}$ & $\begin{array}{c}\text { Increase in } \\
\text { heart rate }(\%)\end{array}$ & \\
Isoproterenol & $39.6 \pm 11.7$ & $29.9 \pm 5.6$ & $(\mathrm{n}=6)$ \\
Aminophylline & $22.9 \pm 4.3$ & $28.1 \pm 4.6$ & $(\mathrm{n}=6)$ \\
Proxyphylline & $40.3+12.6$ & $5.0 \pm 1.1$ & $(\mathrm{n}=6)$ \\
Theoesberiven & $29.8 \pm 5.6$ & $9.8 \pm 1.3$ & $(\mathrm{n}=8)$ \\
\hline
\end{tabular}

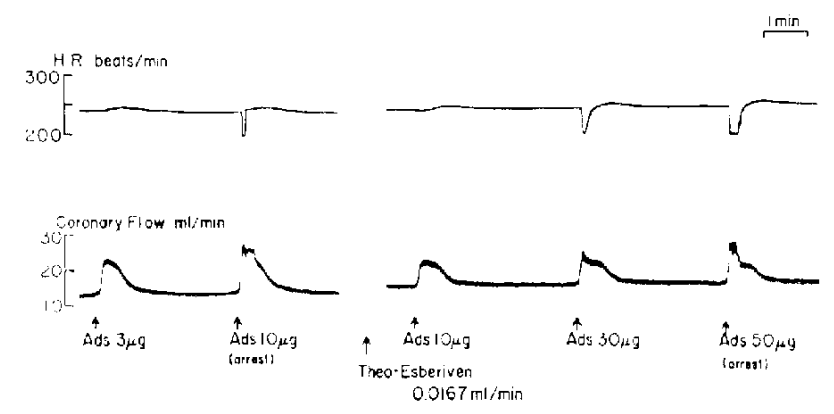

FIG. 9. Antagonistic effect of theoesberiven towards adenosine. Isolated perfused heart preparation of the guinea pig. HR: heart rate per minute. Ads: adenosine. 


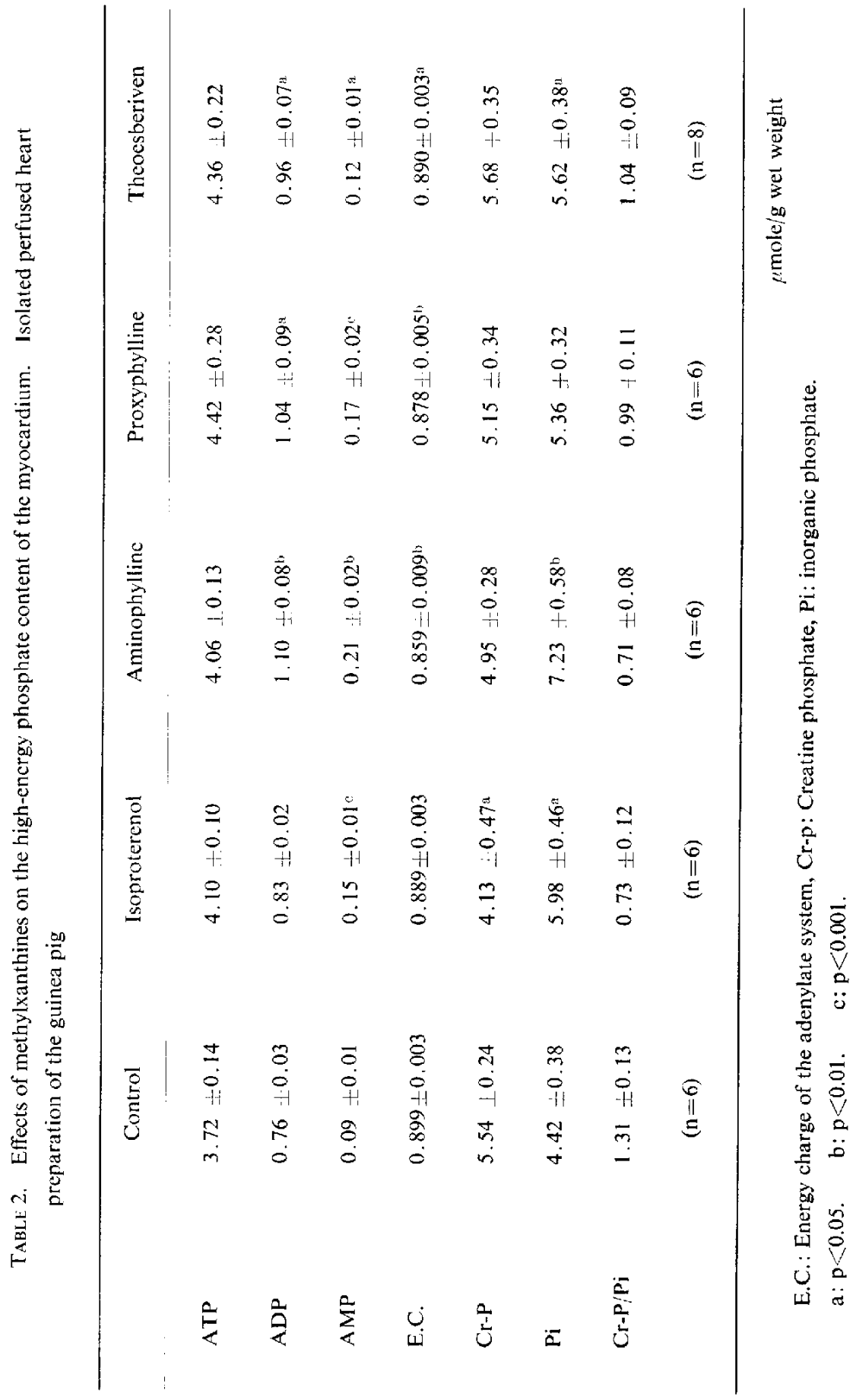


again the positive chronotropic effects were minimal with proxyphylline and theoesberiven, as compared with an increase in the coronary flow. Aminophylline produced a marked increase in the heart rate in this preparation.

Adenosine produced a marked increase in the coronary flow associated with a decrease in the heart rate (and atrioventricular conduction block at higher doses). All three methylxanthines were found to be antagonistic towards adenosine. As a representative record, the effect of theoesberiven is depicted in Fig. 9.

Table 2 summarizes the effects of aminophylline, proxyphylline and theoesberiven on the high-energy phosphate compounds of the isolated perfused heart preparation of the guinea pig. For comparison, the effects of isoproterenol are also shown in this table. A reduction of creatine phosphate content was observed after isoproterenol, while there was a slight increase in ATP content. Though much smaller, a decrease in crcatine phosphate was also observed after aminophylline and proxyphylline. Proxyphylline and theoesberiven produced an increase in ATP content, while the increase was minimal after aminophylline.

\section{Isolated left atrial preparation of the guinea pig}

The dose response curve for the positive inotropic effect of isoproterenol was shifted to the left after pretreatment of the preparation with aminophylline, a phosphodiesterase inhibitor, while proxyphylline and theoesberiven did not produce an appreciable shift. Fig. 10 represents a typical example of the shift to the left of the dose response curve produced

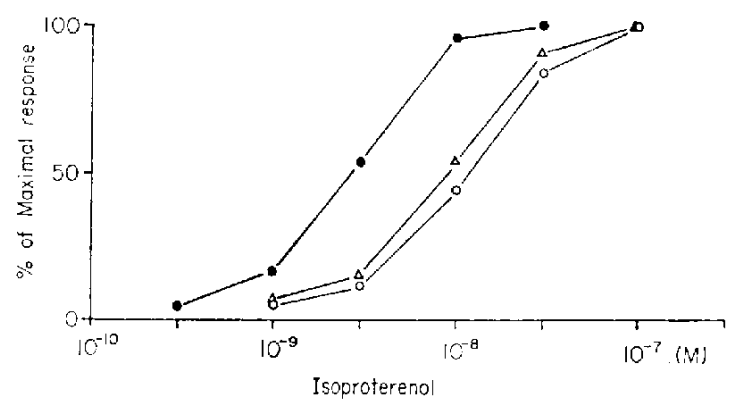

FIG. 10. Effects of aminophylline and proxyphylline on the positive inotropic effect of isoproterenol in the isolated left atrial preparation of the guinea pig. Open circles: control (isoproterenol alone). Closed circles: after pretreatment of the preparation with $10^{-4} \mathrm{M}$ of aminophylline. Triangles: after pretreatment of the preparation with $10^{-4} \mathrm{M}$ of proxyphylline.

TABLE 3. Influence of aminophylline and proxyphylline on the $\mathrm{pD}_{\text {-values of }}$ isoproterenol

\begin{tabular}{lccc} 
& No. of exp. & Control & Treated \\
Aminophylline $10^{4} \mathrm{M}$ & 7 & $8.05 \ldots 0.05$ & $8.50 \perp 0.05 \div, 1)$ \\
Proxyphyllinc $10^{-4} \mathrm{M}$ & 5 & 7.98 .0 .09 & $8.10 \pm 0.10$ \\
\hline
\end{tabular}

Mean values -1 S.E.

a) $p 0.001$ compared with control.

b) $\mathrm{p}<0.005$ compared with proxyphylline treated. 
by aminophylline in comparison with that of proxyphylline. Changes in the $\mathrm{pD}_{2}$ values of isoproterenol produced by these two methylxanthines are listed in Table 3.

\section{DISCUSSION}

The present experiments clcarly demonstrate that methylxanthines produced an improvement of the oxygen supply to the myocardium, despite the fact that these substances induced an increase in the myocardial oxygen consumption. Particularly significant were the results obtained with proxyphylline and theoesberiven; the increase in the myocardial oxygen consumption was minimal with these two compounds and corresponded to the minimal increase in the heart rate produced with these same two compounds. Thus, it is clear that methylxanthines should be catcgorized not as "malignant" vasodilators as proposed by Schmidt (4), but as "benign" vasodilators. There was also an improvement of the mechanical efficiency after these two compounds.

Myocardial redox potential ( $A \mathrm{Eh}$ ) changed to more negative values after all the three methylxanthines tested, although the effects produced by proxyphylline and theoesberiven were not remarkable. Since myocardial hypoxia is not conceivable, at least in HLP's with these compounds, as discussed in the foregoing, it may be reasonable to assume that the debasement of $\Delta$ Eh resulted not from a hypoxia of the myocardium, but from an augmented glycogenolysis (16), for isoproterenol-induced debasement of $J$ Eh persisted after abolishment of the positive inotropic and chronotropic effects of this substance by practolol and, therefore, in the absence of the increase in the myocardial oxygen consumption. As a common mechanism, an accumulation of cyclic AMP within the myocardium can be invoked, since it is well known that methylxanthines are potent inhibitors of phosphodiesterase (11). Indeed, it was demonstrated in the present experiment that aminophylline produced a definite potentiation of the effect of isoproterenol. The fact that proxyphylline and theoesberiven did not produce an appreciable potentiation of the effect of isoproterenol is compatible with this interpretation.

Although numerous changes were found in the content of myocardial high energy phosphate compounds content after methylxanthines, emphasis cannot be placed on these individual findings, since myocardial edema developed in the isolated saline perfused heart preparation used in the present study and the degree of the edema was quite variable. We, therefore, calculated the creatine phosphate $(\mathrm{Cr}-\mathrm{P}) /(\mathrm{Cr}-\mathrm{p}-$ inorganic phosphate $(\mathrm{Pi})$ ratio and the energy charge. The energy charge of the adrenylate system is calculated as (ATP+ $1 / 2 \mathrm{ADP})$ (ATP -ADP + AMP), according to the concept developed by Atkinson and Walton (17). This value represents the high energy portion within the total adenine nucleotides and is thought to reflect an intact myocardial energy metabolism better than individual concentrations of the adenine nucleotides do. $\mathrm{Cr}-\mathrm{P} /(\mathrm{Cr}-\mathrm{P} \div \mathrm{Pi})$ ratio decreased after all the methylxanthine derivatives used as well as after isoproterenol (Isp), in the following order: Isp = aminophylline $(\mathrm{AMPH})>$ proxyphylline = theoesberiven. Compared to changes in the $\mathrm{Cr}-\mathrm{P} /(\mathrm{Cr}-\mathrm{P} \mid \mathrm{Pi})$ ratio, changes in the energy charge were small and minimal with most of the compounds; a significant decrease was observed only after AMPH. These findings are 
in agreement with the conclusion reached through the analysis of the relation between the myocardial oxygen consumption and the coronary blood flow observed in the canine HLP's except AMPH, which, unlike Isp, produced an improvement of the oxygen supply to the myocardium in dog HLP's. This discrepancy is attributed to a much greater increase in the heart rate induced in the isolated perfused heart preparation of the guinea pig as compared with a minimal increase in dog HLP's. Whether this represents a species difference or a difference in the experimental methods is not clear at present.

\section{REFERENCES}

1) Boyer, N.H. and Green, H.D.: Am. Heart J. 21, 199 (1941)

2) Wégria, R.: Pharmacol. Rev. 3, 197 (1951)

3) Charlier, R.: Coronary Vasodilators, Pergamon Press, Oxford (1961)

4) Schmidt, C.F.: Trans. Am. Coll. Cardiol. 1, 89 (1951)

5) Charlier, R.: Handb. exp. Pharmacol. 31, 152 (1971)

6) Russek, H.I.: Am. J. med. Sci. 239, 187 (1960)

7) Taugner, R., von Bubnoff, M., Weth, H., Waltz, H., Hochrein, H., Bartels, M. and SCHMID, E.: Arzneim.-Forsch. 6, 601 (1956)

8) Roth, F.E., Winbury, M.M. and Govier, W.M.: J. Pharmacol. exp. Ther. 121, 487 (1957)

9) De Gubareff, T. and Sleator, W.: J. Pharmacol. exp. Ther. 148, 202 (1965)

10) Afonso, S.: Circulation Res. 26, 743 (1970)

11) Butcher, R.W. and Sutherland, E.W.: J. biol. Chem. 237, 1244 (1962)

12) Imai, S., Otorit, T., Takfda, K. And Katano, Y.: Japan. J. Pharmacol. 25, 423 (1975)

13) Jones, C.E., Parker, J.C. AND Smith, E.E.: J. Chromat. 64, 378 (1972)

14) Fiske, C.H. AND SUBBaRow, Y.: J. biol. Chem. 66, 375 (1925)

15) Fawaz, G. ANd Fawaz, E.N.: Methods in Pharmacology, Edited by Schwartz, A., Vol. 1., p. 515, Appleton-Century-Crofts, New York (1971)

16) Otori, T., Takeda, K., Katano, Y., Nakagawa, Y. and Imai, S. : Japan. J. Pharmacol. 27, $573(1977)$

17) Atkinson, D.E. and Walton, G.M.: J. biol. Chem. 242, 3239 (1967) 